\title{
An Experimental Analysis on Nusselt Number of Natural Circulation Flow in Transient Condition Based on the Height Differences between Heater and Cooler
}

\author{
M. Juarsa*, J.P. Witoko, Giarno, D. Haryanto and J.H. Purba \\ Center for Nuclear Reactor Technology and Safety, National Nuclear Energy Agency, \\ Puspiptek Area Serpong, Tangerang Selatan 15130, Indonesia
}

\section{ARTICLE INFO}

Article history:

Received 31 October 2016

Received in revised form 13 April 2018

Accepted 17 April 2018

\section{Keywords:}

Nusselt

Heat transfer

Transient

Height difference

Natural circulation

\begin{abstract}
A B S T R A C T
A better understanding on the phenomenon of natural circulation flow for cooling systems is necessary prior to improving the safety of nuclear power plant, not only in normal operation but also in accident conditions. One way to understand this phenomenon is by analyzing the Nusselt number in various geometrical dimensions through experimentation. The purpose of this study is to understand natural circulation phenomenon in transient condition by varying height differences between heater and cooler. To achieve this purpose, an experiment apparatus called NC-Queen was developed and arranged to enable three variations of height differences between heater and cooler, i.e., $1.4 \mathrm{~m}, 1.0 \mathrm{~m}$, and $0.3 \mathrm{~m}$. It is made of a stainless steel tube with a diameter of 1 inch, arranged in rectangular shape $6.4 \mathrm{~m}$ in length, and uses water as coolant. The initial temperature of the heater was set at $90{ }^{\circ} \mathrm{C}$. The Nusselt number was obtained by calculating the flow rate as a function of transient temperature. The results confirm that height differences affect thermal properties and flow region based kinetics characteristics of water. In initial condition, decreasing height difference from $1.4 \mathrm{~m}$ to $1.0 \mathrm{~m}$ resulted in flow rate reduction of $16.7 \%$, while decreasing height difference from $1.4 \mathrm{~m}$ to $0.3 \mathrm{~m}$ resulted in a $39.1 \%$ flow rate reduction. In final condition, the flow rate reductions were $75 \%$ and $82.6 \%$, respectively. Meanwhile, in initial condition, the Nusselt number for height difference reduction from $1.4 \mathrm{~m}$ to $1.0 \mathrm{~m}$ and from $1.4 \mathrm{~m}$ to $0.3 \mathrm{~m}$ decreased by $30.5 \%$ and $74.6 \%$, respectively, while for final condition, the Nusselt number decreased by $11.9 \%$ and $67.4 \%$, respectively. The new constants in relationship between Nusselt number and the height difference are $a=20.06$ and $b=0.56$. The dominance of turbulent flow provides a good safety margin with indications of the large amount of heat released.
\end{abstract}

(C) 2018 Atom Indonesia. All rights reserved

\section{INTRODUCTION}

One alternative means to obtain a large amount of electrical energy to overcome the deficit of electricity in Indonesia is by operating nuclear power plants (NPPs). However, the use of NPPs has a potential hazard such as the possibility of radioactive material releases. The BWR-type NPP accident in 2011 at Fukushima, Japan, is the second severe accident of the LWR (light water reactor)

${ }^{*}$ Corresponding author.

E-mail address: juars@batan.go.id

DOI: https://doi.org/10.17146/aij.2018.876 after the PWR-type NPP accident at TMI, Pennsylvania, USA, in 1979. Although the initial cause of the Fukushima accident was an earthquake, the failure of reactor core cooling systems, caused by the diesel generator backup power submergence by a tsunami, was the initiator of the severe accident. The active cooling systems using pumps failed to remove decay heat from the core to prevent the reactor core from melting. Therefore, for the future, there is a need for the development of the reactor core cooling system (RCCS) that, when an accident occurs, functions using natural circulation flow without power (non-electrical cooling system). 
This passive cooling system becomes an issue and the future direction of thermal-hydraulics $\mathrm{R} \& \mathrm{D}[1]$.

The concept of passive systems is that fluid flows not due to any intervention from an external forces, but based on the laws of nature. The phenomenon of fluid flow in the passive system, known as natural circulation, occurs by, for example, fluid density differences [2]. The effect of fluid density changes in hot regions will lead to buoyancy force and the effect of fluid density changes in cold regions will cause changes in gravitational force. Thus, the implementation of passive systems in a nuclear power plant can be used for both normal and abnormal conditions (accident, transient) [3]. Before the accident of nuclear power plant in Fukushima Daiichi, the concept of passive safety systems had been developed and introduced into the latest NPPs such as the ESBWR and the AP1000 [1]. Generation III+ reactor designs (including the AP1000) have been equipped with passive safety systems [4,5], which is the result of the evolution of safety technology design of nuclear power plants [6].

Several researchers have investigated natural circulation phenomenon since several decades ago. The research activities they have performed are intended to evolve the reactor safety system by implementing their study into a passive residual heat removal system (PRHRS). The effects of buoyancy force, the loss of pressure, and the friction in the pipes against the driving force of fluid flow have been investigated [7]. Later, Dobson [8] proposed a simple equation to represent the characteristics of a non-linear and transient flow in a loop during a natural circulation flow to explain the single-phase and laminar flow conditions. Moreover, the stability and instability flow oscillation in the loop of natural circulation have been investigated through experiments and computer simulations $[9,10]$. The phenomenon of natural circulation under general geometries and its applications have been investigated by Vijayan et al. [2,9], Zvirin [11], and D'Auria et al. [12]. Their research activities were conducted in rectangular-shaped pipes with open and closed loops and steady state conditions. The steady-state and transient flows have been investigated by analyzing the stability of the system due to the variations of water temperatures in the heater and in the cooler. In another research, Misale et al. [13,14] have considered the different thermal boundary conditions, such as the height difference between the heater and the cooler regions.
The effect of heat transfer in the pipeline on the mass flow rate parameters during natural circulation has been studied by several researchers [13-18].

Several studies to analyze non-dimensional numbers have also been conducted. Vijayan et al. [17] examined the stability of the natural circulation of the single-phase rectangular loop for various orientations of heater and cooler. Then, Devia et al. [15] conducted studies to evaluate the mass and heat flow to determine the flow stability in the loop with no variations in the heater and cooler. Meanwhile, Jiang and Shoji [19] and Guo et al. [20] conducted the study on the cooling system performance with several parameters such as the diameter, length, and angle of inclination. Wang et al. [21] studied the heat transfer characteristics of the natural circulation conditions based on the relationships of thermal characteristics before and after the rolling and the relationship between the relative pulsation amplitude for Nusselt number and Reynolds number with parameter motion rolling. Vijayan et al. $[9,17]$ has performed an analysis of Grashof numbers using Stanton numbers in rectangular pipe loop prior to study variations in heater and cooler.

However, the works described above were performed in steady state conditions. This study was conducted to understand natural circulation phenomenon in transient conditions. The Nusselt number was determined to investigate heat transfer behavior of the cooling system. In order to realize this objective, an experiment using NC-Queen has been conducted in transient condition by varying the height difference between the heater and the cooler, as a continuation of our previous work that varied initial water temperature in the heater [22].

\section{EXPERIMENTAL METHODS}

\section{Experiment facility}

An experiment facility called NC-Queen was constructed to simulate the cooling system by natural circulation at the thermalhydraulics experimental laboratory. The NC-Queen consists of materials and equipment such as a heater, a cooler, an expansion tank, a refrigerator, 13 type K (TC1 to TC13) thermocouples, SS316 tubes with a diameter of 1 inch, and water as a working fluid. Other support tools were computers and NI-DAQ 9188 to record and storage data generated by the experimentation. 
The experimental setup for this research can be seen in Fig. 1.

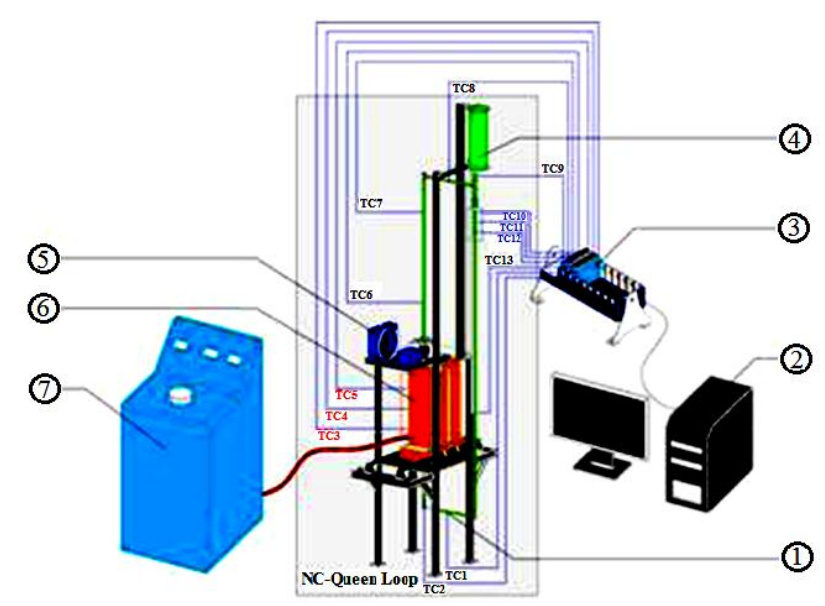

Fig. 1. Experimental setup of NC-Queen loop [22].

Figure 1 shows the NC-Queen loop, consisting of: (1) A loop of rectangular SS316 tubes with a diameter of 1 inch, (2) personal computer, (3) data acquisition system (cDaq 9188 CompactDAQ chassis and NI 9213 temperature input module, both from National Instruments), (4) expansion tank, (5) refrigerant as a cooler, (6) heating section (heater) and (7) a $25-\mathrm{kW}$ voltage regulator.

\section{Experiment procedure}

The first step of the procedure was to check the completeness of the experimental devices of NC-Queen loop. The rectangular loop of NC-Queen geometry has a size of $2.7 \mathrm{~m} \times 0.5 \mathrm{~m}$, as shown in Fig. 2.

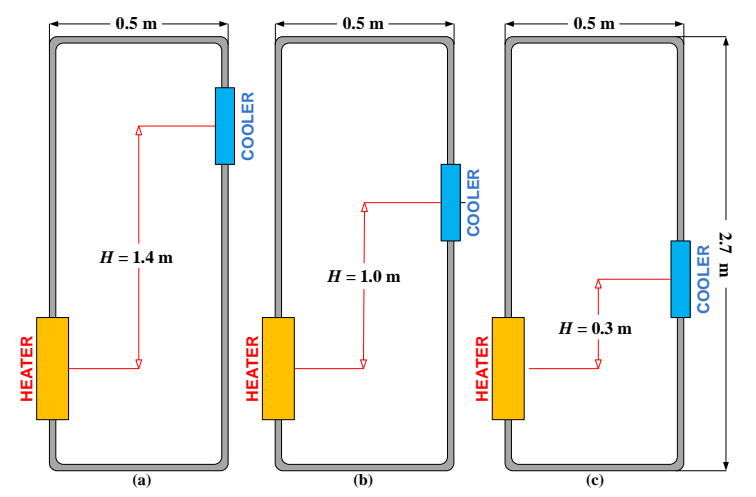

Fig. 2. Variations of height difference between heater and cooler.

Then, the loop was filled with water until there were no air bubbles in the NC-Queen loop and it did not leak. Experimental variations were based on three variations of height difference between the heater and the cooler, namely (a) $1.4 \mathrm{~m}$, (b) $1.0 \mathrm{~m}$, and (c) $0.5 \mathrm{~m}$. The variations of the height difference for the heater and cooler are shown in Fig. 2. The total length $(L)$ of the rectangular loop is $6.4 \mathrm{~m}$. At the beginning, the water in heater region was heated until the initial water temperature around $80{ }^{\circ} \mathrm{C}-90{ }^{\circ} \mathrm{C}$. Afterward, the cooler was turned on and heater was turned off. Transient temperature data during experiment was recorded after the cooler ran and the heater was turned off.

Temperature data was recorded using NI-Daq (National Instrument) through LabVIEW program for the experiment purposes. K-type thermocouples were used with measurement error around $0.2 \%$. Later, the experiment was repeated with the height differences of $1.4 \mathrm{~m}, 1.0 \mathrm{~m}$, and $0.3 \mathrm{~m}$.

\section{Calculation and analysis}

\section{Calculation}

Temperature data used for the analysis was taken from thermocouple measurement at six points. Three of those thermocouples, i.e., TC3, TC4, and TC5, were located in the heater, and the other three, i.e., TC10, TC11, and TC12, in the cooler. The flow rate was calculated using data measured by those six thermocouples and inserted into equation (1) [12-14,16].

$$
v=\frac{-64 \mu L+\sqrt{(64 \mu L)^{2}+8 g H K \rho\left(\rho_{h}-\rho_{c}\right) D^{4}}}{2 D^{2} \rho K}
$$

Calculation was performed using equation (1) using transient temperature data captured during experiment. The data was recorded from transient temperature measurement and then processed using National Instrument (NI) data acquisition system.

Then, Reynolds numbers were calculated by inserting parameters of flow rate, tube diameter, and the thermal properties of water into equation (2):

$$
\operatorname{Re}=\frac{\rho_{a} v D}{\mu}
$$

If the Reynolds number was less than 2000, the fluid flow in the loop was laminar and if the Reynolds number was greater than 4000, the fluid flow was considered turbulent. Then, if the Reynolds number was between 2000 and 4000, the fluid flow was transitional. The calculation of the Nusselt number was then performed using the Reynolds number and the Prandtl number obtained from water thermal properties. If the Reynods 
number indicated turbulence, the Nusselt number was then be calculated using equation (3), while if laminarity was indicated, Nusselt number was calculated using equation (4). For the two flow conditions, equation (5) can be used as a general representation of flow conditions.

$$
\begin{aligned}
& N u_{T}=0.023(\operatorname{Re})^{4 / 5} \operatorname{Pr}^{n} \\
& N u_{L}=3.66(\operatorname{Re} \cdot \operatorname{Pr})^{1 / 3}\left(\frac{D}{L}\right)^{1 / 3} \\
& N u_{\text {ave }}=C \operatorname{Re}^{m} \operatorname{Pr}^{n}
\end{aligned}
$$

with $C, m$ and $n$ being constant number generated from experimental data.

\section{Analysis}

In the analysis of Nusselt number and height differences $(H)$, some mathematical substitutions were done. The relationship between Nusselt number and height difference was defined using equation (1) and (2) which are substituted into equation (4). The first step is to substitute equation (1) into equation (2), resulting in:

$$
\begin{aligned}
\operatorname{Re} & =-\frac{32}{K}(L / D)+\left[\left(\frac{32}{K}(L / D)^{2}\right)^{2}+\frac{2 g \rho\left(\rho_{h}-\rho_{c}\right) D^{2}}{\mu^{2} K} H\right]^{0.5}, \text { if } \\
x & =\frac{32}{K}(L / D) \text { and } y=\frac{2 g \rho\left(\rho_{h}-\rho_{c}\right) D^{2}}{\mu^{2} K},
\end{aligned}
$$

then

$$
\operatorname{Re}=-x+\left(x^{2}+y H\right)^{0.5}
$$

After equation (6) is substituted into equation (5), the following equation is obtained,

$$
N u_{\text {ave }}=C\left(-x+\left(x^{2}+y H\right)^{0.5}\right)^{m} \operatorname{Pr}^{n}
$$

Finally, the simplicity of equation (5) as a function of height differences becomes,

$$
N u_{\text {ave }} \simeq c H^{m}
$$

Equation (7) means that the parameters of temperature, loop length $(L)$, and tube diameter $(D)$ are assumed as a constant for the temperature of $90{ }^{\circ} \mathrm{C}$. Equation (7) as a function of height differences is called Power function. This function will be used to perform curve fitting for Nusselt number versus variations of height difference between heater and cooler.

\section{RESULT AND DISCUSSION}

\section{Temperature characteristics}

The experiments of natural circulation flow in one-phase condition using NC-Queen loop with three variations of the height differences showed the characteristics of temperature during transient condition. Data was recorded since water temperature in heater area reaches $90{ }^{\circ} \mathrm{C}$ and the recording was stopped once the temperatures of TC3, TC4, TC5, TC10, TC11, and TC12 were stable. The height difference of heater and cooler shows three different temperatures characteristics during the cooling process in transient conditions, as shown in Figs. 3(a), 3(b) and 3(c).

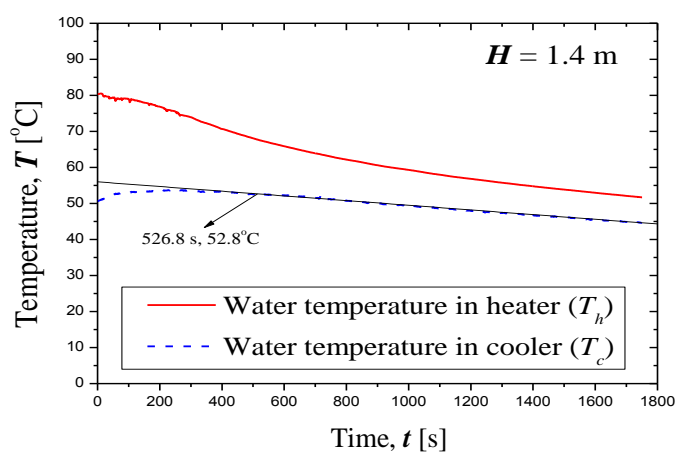

(a) Height Difference $=1.4 \mathrm{~m}$

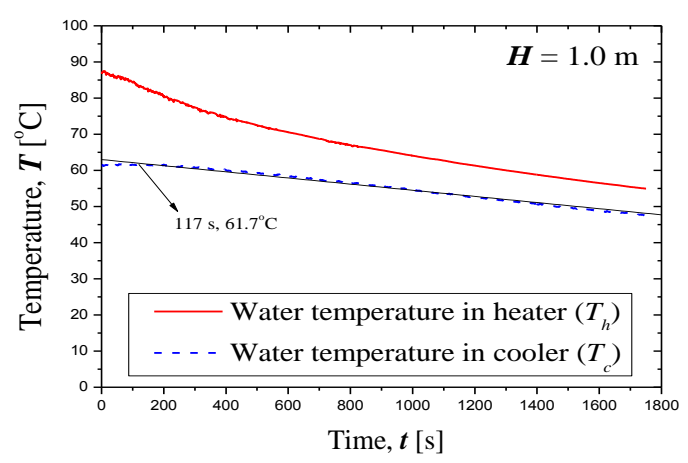

(b) Height Difference $=1.0 \mathrm{~m}$

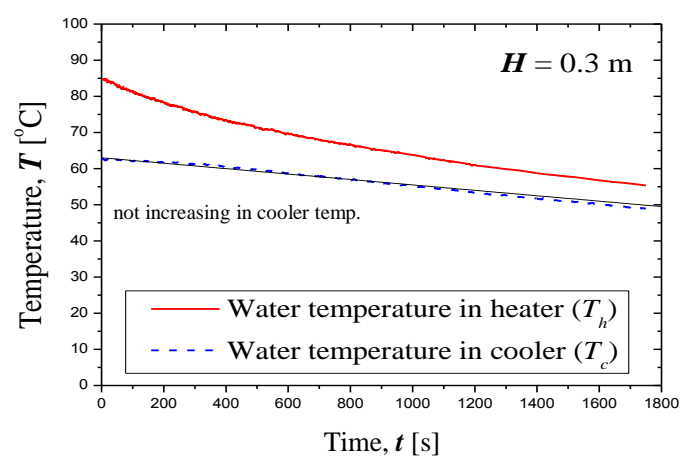

(c) Height Difference $=0.3 \mathrm{~m}$

Fig. 3. Temperature characteristics versus time for three height differences between heater and cooler. 
Figures 3(a)-3(c) show that within 1800 seconds the temperatures of heater and cooler decreased transiently until it reached an average temperature of between $50{ }^{\circ} \mathrm{C}$ and $70{ }^{\circ} \mathrm{C}$ in the final state. It means that in 1800 seconds, while there were three distinct values of height difference, the final states were reached at almost the same temperature. When temperature in the heater decreased, the temperature in cooler also decreased due to the heat transfer from the heater to the cooler by convection. The mechanisms of conduction and convection heat transfer were more dominant than the radiation heat transfer mechanism. This can be explained, that for the height difference of $1.4 \mathrm{~m}$, less time was needed to achieve a stable temperature (Fig. 3a). However, the stable temperatures at the height difference of $1.0 \mathrm{~m}$ were higher than the stable temperatures at $1.4 \mathrm{~m}$ height difference (Fig. 3b). At height difference of $1.0 \mathrm{~m}$, more time was needed than at the height difference of $1.4 \mathrm{~m}$, and less time than at the height difference of $0.3 \mathrm{~m}$ (Fig. 3c) to achieve a stable temperature.

In the state, Fig. 3(a)-Fig. 3(c) show that only the curves for the height difference of $1.4 \mathrm{~m}$ for the water temperature in the cooler had a different profile compared with $1.0 \mathrm{~m}$ and $0.3 \mathrm{~m}$. For the height difference of $1.4 \mathrm{~m}$, the profile of the graph shows that from 0 to $526.8 \mathrm{~s}$, the temperature in the cooler increased by $2.8^{\circ} \mathrm{C}$, and then temperature decreased. Meanwhile, for the height difference of $1.0 \mathrm{~m}$, the temperature profile in cooler show an increase of $0.29^{\circ} \mathrm{C}$. However, for the height difference of $0.3 \mathrm{~m}$, there was no temperature increase since the beginning. It appears that although at $0 \mathrm{~s}$ the water temperatures in the cooler at the height difference of $1.0 \mathrm{~m}$ and $0.3 \mathrm{~m}$ were higher than at the height difference of $1.4 \mathrm{~m}$, the margin of the temperature increase and the temperature gradient for the height difference of $1.4 \mathrm{~m}$ was higher than for $1.0 \mathrm{~m}$ and $0.3 \mathrm{~m}$. The condition shows the influence of the height difference on the profile of transient temperature change in the cooler.

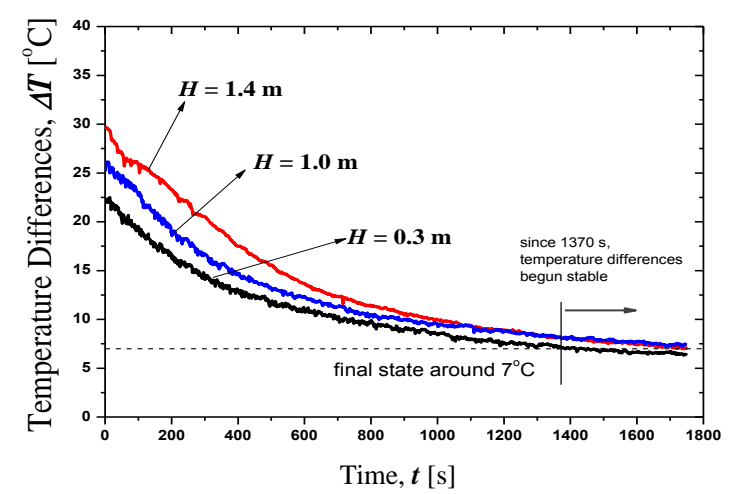

Fig. 4. Temperature differences between heater and cooler versus time.
When the temperature in the cooler was subtracted from temperature in the heater for each height difference, as seen in Fig. 4, it is clear that there was a significant change in the gradient of temperature starting from $0 \mathrm{~s}$ to $1370 \mathrm{~s}$. From $1370 \mathrm{~s}$ to $1800 \mathrm{~s}$, all temperature profiles are almost the same. The average temperature difference for all height difference variations was around $7{ }^{\circ} \mathrm{C}$. This means that the height difference variation strongly influenced energy transfer rate from heater to cooler area. The prediction of stable temperature at $1370 \mathrm{~s}$ must be validated using Reynolds number which is presented in the next section.

\section{Water flow rate}

Water flow rate is calculated using equation (1). The flow rate changed continually. Flow rate is calculated as the average flow in loop between the heater and the cooler. The calculation of water flow rate was done for each height difference between heater and cooler. The overall water flow rate is shown in Fig. 5. In this study, as shown in Fig. 5, the stability of the flow cannot be determined through the curve. The water flow rate at the beginning for height difference of $1.4 \mathrm{~m}$ was higher than for height differences of $1 \mathrm{~m}$ and $0.3 \mathrm{~m}$, even though at the beginning, all initial temperatures for three variations of height difference are almost the same.

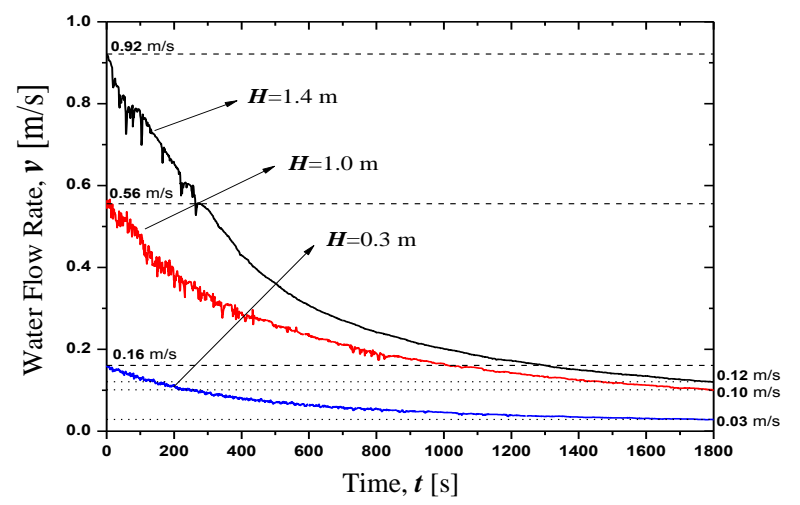

Fig. 5. Water flow rate versus time of three height differences between heater and cooler.

In Fig. 5 for height differences of $1.4 \mathrm{~m}$, $1.0 \mathrm{~m}$, and $0.3 \mathrm{~m}$, the initial water flow velocities were $0.92 \mathrm{~m} / \mathrm{s}, 0.56 \mathrm{~m} / \mathrm{s}$, and $0.16 \mathrm{~m} / \mathrm{s}$, respectively, while the final water flow velocities were $0.12 \mathrm{~m} / \mathrm{s}$, $0.10 \mathrm{~m} / \mathrm{s}$, and $0.03 \mathrm{~m} / \mathrm{s}$. As mentioned previously, in the final condition, water flow velocities for height difference of $1.4 \mathrm{~m}$ and $1.0 \mathrm{~m}$ were almost similar, different only by $16.7 \%$. The influence of the variation of height difference between heater and cooler on the water flow rate is dominant. The difference between $1.4 \mathrm{~m}$ and $1.0 \mathrm{~m}$ was only 
$28.6 \%$, compared with the $78.6 \%$ difference between $1.4 \mathrm{~m}$ and $0.3 \mathrm{~m}$. Gravitational force as a driving force at the beginning is very strong, and it depends on the height difference. The decrease in flow velocities from the value for $1.4 \mathrm{~m}$ height difference to $1.0 \mathrm{~m}$ was $39.1 \%$ at initial condition, while from height $1.4 \mathrm{~m}$ to $0.3 \mathrm{~m}$, it was $82.6 \%$. Those decrease to $16.7 \%$ and $75 \%$, respectively, for the final condition.

\section{Reynolds number}

In this study, the Reynolds numbers were calculated using equation (2) from temperature difference data for each height difference as seen from Fig. 5. The calculation results for Reynolds numbers are shown in Fig. 6. Dynamics viscosity and average water density as a temperature function, as well as the tube diameter of 1 inch, were also used in this calculation. The evolution of Reynolds number with time can also show the amount of heat released during the transient cooling process.

The pattern of Reynolds number decrease in transient condition in Fig. 6 shows that there were three regional divisions based of Reynolds numbers. The flow region with Reynolds number over 4000 is turbulent, 2000-4000 is transitional, and below 2000 is laminar. In this research, although the experiment was conducted in transient condition, there were situations that could be defined as stable flow. The stable flow was defined as transitional flow area including laminar flow area. In this case, the flow with Reynolds number above 4000 could be categorized as turbulent flow and transitional flow region.

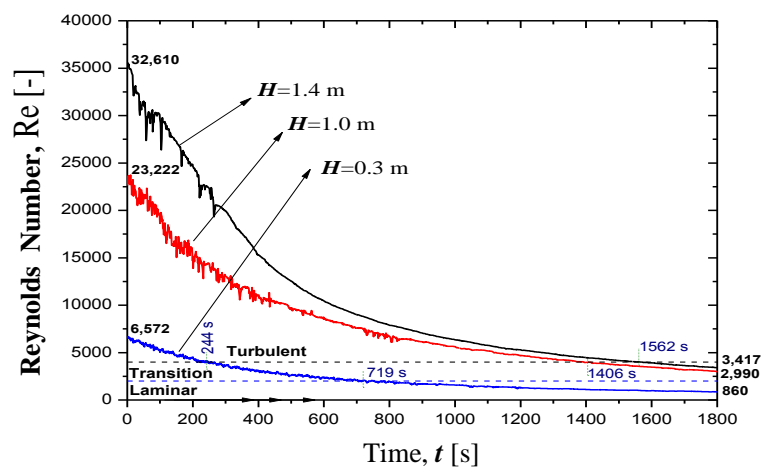

Fig. 6. Reynolds number versus time for three height differences between heater and cooler.

Figure 6 also shows time points that are used to separate the flow areas based on Reynolds numbers. The flow at the height difference of $1.4 \mathrm{~m}$ from $0 \mathrm{~s}$ until $1562 \mathrm{~s}$ is transient, and then from $1562 \mathrm{~s}$ until final state at $1800 \mathrm{~s}$ it becomes a stable flow. In the height difference of $1.0 \mathrm{~m}$, transient flow starts from $0 \mathrm{~s}$ until $1406 \mathrm{~s}$, then from $1406 \mathrm{~s}$ until $1800 \mathrm{~s}$ the flow becomes stable. Finally, for the height difference of $0.3 \mathrm{~m}$ the condition is almost stable almost from the beginning, with transient flow occurring from $0 \mathrm{~s}$ until $244 \mathrm{~s}$, and stable flow starting from $244 \mathrm{~s}$ until $1800 \mathrm{~s}$. Based on the description above, the time points can be used as a benchmark to determine the values of Nusselt number in the flow regions.

\section{Nusselt number}

Nusselt number is calculated using equation (4) for laminar and transition flow and equation (5) for turbulent flow. Data on Reynolds number from Fig. 6 and Prandtl number from water thermal properties as a temperature function were used in the two equations to calculate the Nusselt number. The calculation results are shown in Fig. 7.

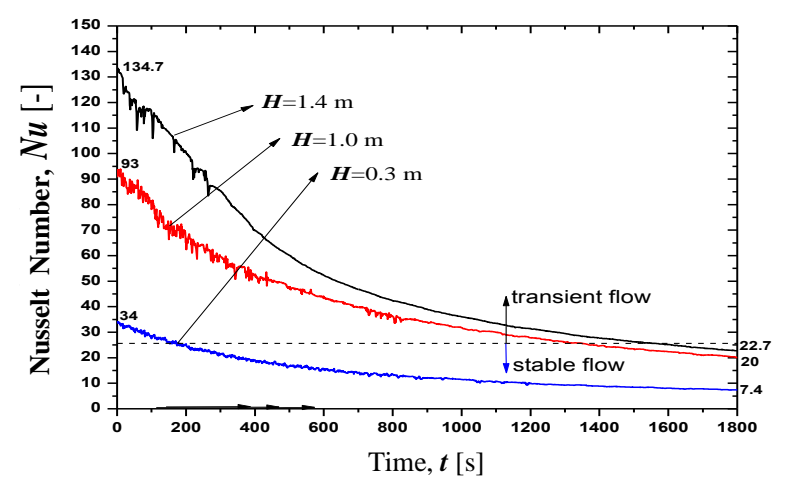

Fig. 7. Nusselt number versus time for three height differences between heater and cooler.

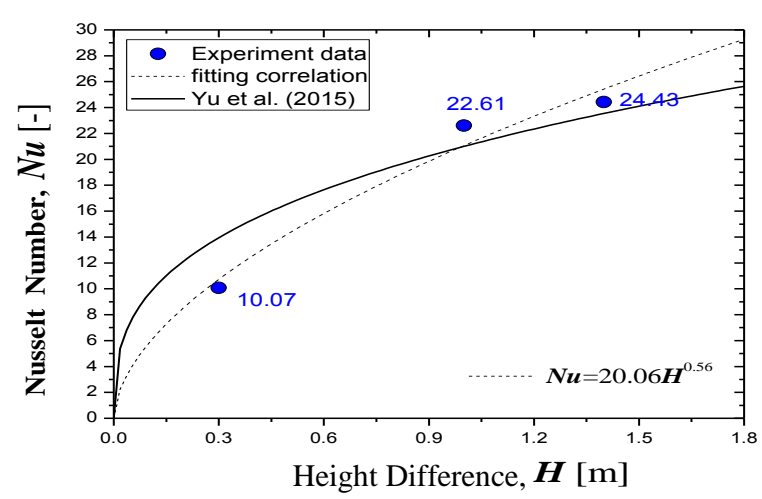

Fig. 8. Average Nusselt number versus height difference.

As seen in Fig. 7, the decline in Nusselt number showed the same phenomenon with the pattern on the Reynolds number during the $1800 \mathrm{~s}$ duration of experiment. The Nusselt number in transient flow and stable flow were calculated based on time points from Reynolds number from Fig. 6 . The decrease in Nusselt number was very large in transient flow that occurred in the area that showed great energy changes as well, that were related to heat transfer coefficient. Fig. 7 also shows that in the beginning, for the height difference of $1.4 \mathrm{~m}$, $1.0 \mathrm{~m}$, and $0.3 \mathrm{~m}$, the Nusselt number are 134.7, 93, 
and 34, respectively. Then, in the final state the Nusselt number are 22.7, 20, and 7.4. In initial condition, comparing the values for the height of $1.4 \mathrm{~m}$ and for the height of $1.0 \mathrm{~m}$, the decrease in Nusselt number was $30.5 \%$, while between $1.4 \mathrm{~m}$ and $0.3 \mathrm{~m}$, the decrease was $74.6 \%$. At condition, the decreases are $11.9 \%$ and $67.4 \%$, respectively.

The effect of the height differences between heater and cooler is related to the convective heat transfer and conductive heat transfer process. Those relationships explain the heat transfer phenomenon during natural circulation in transient cooling process. In convective heat transfer, the differences are indicated by heat transfer coefficient varying linearly with Nusselt number. It means that much heat was released from water into tube wall by convection, then from inner wall to outer wall by conduction, and finally convection from outer wall into the air. As previously mentioned, the Nusselt number in stable flow has been defined from time points by Reynolds number. The average of Nusselt numbers was calculated based on stable flow. Figure 8 shows fitting equation from the average of Nusselt numbers in stable flow versus the height difference of $1.4 \mathrm{~m}, 1.0 \mathrm{~m}$, and $0.3 \mathrm{~m}$, respectively. As previously mentioned, equation (7) was used to fit equation into experimental data by calculating the Nusselt number. Yu et al. [23] have investigated the effect of Nusselt number equation uncertainty for the passive containment cooling system of AP1000, where the steam mass flow rate inside the containment is much higher than the condensation rate. Here, their equation is also compared to the experimental results. As shown in Fig. 8, it seems that Yu et al.'s equation gives similar results to the present study. The effects of geometry, such as height differences between heater and cooler, on Nusselt number are made possible by the increase of buoyancy and gravitation forces related to the increase of height difference. New constants in relationship between Nusselt number and the height difference are $a=20.06$ and $b=0.56$, as shown in Fig. 8. In terms of thermal hydraulics, in relationship between Nusselt number and safety margin for heat released during transient cooling conditions, it can be said that the higher the Nusselt number is, the higher the safety margin is. The dominance of turbulent flow provides a good safety margin with indications of the large amount of heat that has been released into the environment during the cooling transients.

\section{CONCLUSION}

This paper presents an analysis of Nusselt number based on experimental temperature data that was obtained using several equations. From the initial until the final state (in transient process), all data and calculation results showed that the effect of height differences on temperature difference, flow rate, Reynolds number, and Nusselt number are very significant. In initial and final conditions, the decrease in flow rate from height $1.4 \mathrm{~m}$ to $1.0 \mathrm{~m}$ and to $0.3 \mathrm{~m}$ are $39.1 \%$ and $82.6 \%$ at initial condition and $16.7 \%$ and $75 \%$ at final condition. Nusselt numbers decreased by $30.5 \%$ and $74.6 \%$ at initial condition and $11.9 \%$ and $67.4 \%$ at final condition. Geometrical effect, such as the effects of height differences between heater and cooler on flow rate and Nusselt number, are made possible by the increase of buoyancy and gravitation forces related to the increase of height difference. New constants in relationship between Nusselt number and the height difference are $a=20.06$ and $b=0.56$. An equation from other researchers has been used for comparison with the present data. The domination of transient flow gives more attention for the boundary condition of safety margin. Meanwhile, in stable flow, the thermal coefficient could be defined. The dominance of turbulent flow provides a good safety margin with indications of the large amount of heat that has been released into the environment during the cooling transients. However, more work is needed for comparison with the results from other researchers with more variations in geometrical and thermal parameters, also conduct a new scenario experiment with steady-state and transient conditions using medium or large-scale facilities.

\section{ACKNOWLEDGMENT}

The research was funded by the PTKRNBATAN of Indonesia (Funding No. SP DIPA080.01.1.450310/2014). The authors would like to thank the staff members of the Thermal Hydraulics Experimental Laboratory of PTKRN-BATAN for their support during the experiment.

\section{Nomenclature}

\begin{tabular}{|c|c|c|}
\hline$H$ & : & Height difference (m) \\
\hline$D$ & : & Tube diameter $(\mathrm{m})$ \\
\hline$L$ & : & Loop length (m) \\
\hline$T$ & : & Temperature $\left({ }^{\circ} \mathrm{C}\right)$ \\
\hline$K$ & : & Minor loss coefficient (-) \\
\hline$R$ & : & Hydrodynamics resistance $\left(\mathrm{m}^{-4}\right)$ \\
\hline$g$ & : & Gravitational acceleration constans $\left(\mathrm{m} / \mathrm{s}^{2}\right)$ \\
\hline$v$ & : & Flow rate $(\mathrm{m} / \mathrm{s})$ \\
\hline$\rho_{a}$ & : & Average water density $\left(\mathrm{kg} / \mathrm{m}^{3}\right)$ \\
\hline$\rho_{c}$ & : & Cooler water density $\left(\mathrm{kg} / \mathrm{m}^{3}\right)$ \\
\hline$\rho_{h}$ & : & Heater water density $\left(\mathrm{kg} / \mathrm{m}^{3}\right)$ \\
\hline$\mu$ & : & Dynamics viscosity (kg/ms) \\
\hline $\mathrm{Nu}$ & : & Nusselt number (-) \\
\hline $\operatorname{Re}$ & : & Reynolds number (-) \\
\hline $\operatorname{Pr}$ & : & Prandtl number (-) \\
\hline $\begin{array}{l}n, m, \\
a, b\end{array}$ & : & Constants \\
\hline
\end{tabular}




\section{REFERENCES}

1. P. Saha, N. Aksan, J. Andersen et al., Nucl. Eng. Des. 264 (2013) 3.

2. V. Jain, A.K. Nayak, P.K. Vijayan et al., Exp. Therm. Fluid Sci. 34 (2010) 776.

3. Y. Kozmenkov, U. Rohde and A. Manera, Nucl. Eng. Des. 243 (2012) 168.

4. P. Broxtermann and H.J. Allelein, Nucl. Eng. Des. 261 (2013) 326.

5. D. Paladino and J. Dreier, Nucl. Eng. Des. 247 (2012) 212.

6. Y.J. Cho, S.W. Bae, B.U. Bae et al., Nucl. Eng. Des. 248 (2012) 306.

7. H.H. Bau and K.E. Torrance, J. Fluid Mech. 109 (1981) 417. https://doi.org/10.1017/S0022112081001146

8. R.T. Dobson, R\&D J. 9 (1993) 32.

9. P.K. Vijayan, A.K. Nayak, D. Saha et al., Sci. and Technol. Nucl. Install. (2008) 1.

10. P.K. Vijayan, H. Austregesilo and V. Teschendorff, Nucl. Eng. Des. 155 (1995) 623.

11. Y. Zvirin, Nucl. Eng. Des. 67 (1982) 203.

12. F. D'Auria, G.M. Galassi, P. Vigni et al., Nucl. Eng. Des. 132 (1991) 187.
13. M. Misale, P. Garibaldi, J.C. Passos et al., Exp. Therm. Fluid Sci. 31 (2007) 1111.

14. M. Misale, F. Devia and P. Garibaldi, Some Considerations on the Interaction Between the Fluid and Wall Tube During Experiments in a Single-Phase Natural Circulation Loops, Proceedings of the 3rd IASME/WSEAS Int. Conf. on Heat Transfer, Thermal Engineering and Environment (2005) 128.

15. F. Devia and M. Misale, Int. J. Therm. Sci. 59 (2012) 195.

16. F. D'Auria and M. Frogheri, Nucl. Eng. Des. 215 (2002) 111.

17. P.K. Vijayan, M. Sharma and D. Saha, Exp. Therm. Fluid Sci. 31 (2007) 925.

18. P.K. Vijayan, Nucl. Eng. Des. 215 (2002) 139.

19. Y.Y. Jiang and M. Shoji, Nucl. Eng. Des. 222 (2003) 16.

20. C. Guo, T. Wang, X. Hu et al., Exp. Therm. Fluid Sci. 55 (2014) 21.

21. C. Wang, P. Gao, S. Wang et al., Nucl. Eng. Des. 265 (2013) 348.

22. M. Juarsa, J.H. Purba, H.M. Kusuma et al., Atom Indonesia 40 (2014) 141.

23. Y. Yu, S. Wang, F. Niu et al., Prog. Nucl. Energy 79 (2014) 1. 